\title{
AS REDES DE CONTATOS PESSOAIS E AS PRÁTICAS DE INTELIGÊNCIA COMPETITIVA: UM ESTUDO SOBRE A ARQUITETURA DE RELACIONAMENTO EM UMA EMPRESA DE LOGÍSTICA. ${ }^{1}$
}

\author{
THE NETWORKS OF PERSONAL CONTACTS, AND COMPETITIVE \\ INTELLIGENCE PRACTICES: A STUDY ON THE RELATIONSHIP \\ ARCHITECTURE IN A LOGISTICS COMPANY
}

\author{
Leonel Cezar Rodrigues ${ }^{2}$ \\ Ana Cláudia Knoll Zoschke ${ }^{3}$ \\ Saulo Fabiano Amâncio Vieira ${ }^{4}$ \\ Sérgio Gilberto Bonocielle Junior ${ }^{5}$ \\ Ronie Galeano ${ }^{6}$
}

RESUMO: O presente artigo trata das redes sociais, especialmente das redes de contatos pessoais e as atividades de Inteligência Competitiva na ATT Transbordo. Assim, objetiva analisar como as redes sociais são utilizadas para fomentar as práticas de inteligência competitiva em uma empresa de transbordo. Para tanto se realizou um levantamento bibliográfico acerca das redes sociais, tipologias e benefícios, bem como do conceito e processos da inteligência competitiva nas organizações. A pesquisa empírica aqui retratada é um estudo de caso, exploratório e qualitativo. O processamento dos dados, coletados principalmente com entrevistas semi-estruturadas em profundidade, baseou-se em análise de conteúdo. Os principais resultados indicam que as redes de contato pessoais, tanto internas, quanto externas, constituem o mecanismo básico para operação da inteligência competitiva, principal responsável pelo sucesso do negócio da ATT. Foi observada ainda uma contínua expansão das redes sociais internas, com influência no processo decisório da empresa, no sentido das redes inter-pessoais, com alcance externo. Esse conjunto de captação e distribuição da informação, de fato, é que determina a sedimentação e o formato das práticas de IC na ATT.

PALAVRAS-CHAVE: inteligência competitiva; prospecção da informação; redes sociais; comunicação organizacional.

ABSTRACT: This paper focuses on social networks, specifically individual contact networks related to the
competitive intelligence activities at ATT Transbordo, a selected case study corporation. The target is to
analyze how social networks are used to support the competitive intelligence praxis at the enterprise. To do
this, we review the literature on social network and respective typologies. Also, we search for concepts and
processes of competitive intelligence in organizations. We used the case study method for this empiricist
and exploratory research. Data, collected through semi-structured interviews, were processed under
contend analysis. Main results indicate that the individual networks, either internal, as well as external are
the fundamental mechanism of Competitive Intelligence used at Transbordo. Also, we found a continuous
expansion of the network, influencing the internal decision making process, towards external interpersonal
networks. This set of gathering and distributing information, in fact, determines the kind of sedimentation
and the Competitive Intelligence praxis'format at ATT. KEY-WORDS: Competitive Intelligence; information search; social networks; organizational communication. \footnotetext{
dos Santos Editor. Publicado em 26.04.2010.

Organização Responsável pelo periódico: Universidade Regional de Blumenau - FURB - www.furb.br/rn

2 Universidade Nove de Julho - Uninove - leonelcz@gmail.com

${ }^{3}$ Instituto Blumenauense de Ensino Superior - IBES - zoschke@terra.com.br

${ }^{4}$ Universidade estadual de Londrina - UEL - saulo@uel.br

${ }^{5}$ Universidade Estadual de Maringá - junior@attransbordo.com.br

${ }^{6}$ Faculdade Metropolitana de Maringá - roniegaleano@pop.com.br
}

${ }^{1}$ Artigo Recebido em 30.11.2009. Revisado por pares em 07.04.2009. Recomendado em 12.03.2010 por Leomar 


\section{INTRODUÇÃO}

$\mathrm{O}$ crescimento do estudo sobre redes cresceu exponencialmente em todo o mundo nos últimos anos devido ao grande número de publicações sobre o assunto em todos os campos do conhecimento. Este crescimento foi provocado pelo surgimento da economia da Informação e do Conhecimento, onde em parte, a competitividade das organizações está relacionada ao uso que essas organizações fazem de suas redes. Quanto maior a abrangência das redes, maior a possibilidade de ganhos que a organização poderá obter, seja por meio da coleta de informações estratégicas para o seu negócio, seja como forma de transferência de conhecimento na própria organização.

Nesse contexto, a Inteligência Competitiva (IC), uma ferramenta básica de coleta e disseminação da informação para tomada de decisão, pode minimizar as incertezas do ambiente, provocadas pela alta competitividade de avanços tecnológicos nos mais diversos setores. A IC estrutura-se a partir de dados e informações coletados em bases cognitivas públicas para responder às necessidades tecnológicas de uma organização. Nesse processo, um instrumento de canalização e otimização da coleta de informação, podem ser as redes sociais. As bases cognitivas oferecem dados e informações sobre relatórios internos, pesquisas e dados mercadológicos que muitas vezes estão ao alcance dos concorrentes e que são de fácil acesso. Já as redes sociais, mais especificamente, as redes de contato pessoais auxiliam o desenvolvimento da IC trazendo dados e informações de difícil acesso, ou seja, dados e informações relativas ao conhecimento da organização e de seu entorno que não estão em bases de dados, mas sim nas pessoas e indivíduos. A proximidade e os laços de confiança são fundamentais para que esse tipo de informação seja captado e utilizado pela organização.

Apesar da importância da arquitetura de relacionamento para o desenvolvimento da IC nas organizações, percebe-se que poucos estudos evidenciam essa temática devido à informalidade e complexidade na estruturação dessas redes.

Essa situação pode ser transposta para o setor logístico, em particular para a cadeia logística focada na exportação de commodities agrícolas. Esta cadeia é responsável por grande parte do escoamento da produção nacional de commodities para exportação, que são os principais produtos comercializados no exterior, possuindo significativa relevância para manutenção da balança comercial do país positiva.

Tendo como ponto de partida as considerações expostas, buscou-se, com o presente artigo, analisar como as redes de contatos sociais são utilizadas para fomentar as práticas de IC em uma empresa de transbordo do Paraná.

\section{REDES SOCIAIS: DEFINIÇÕES, TIPOS E BENEFÍCIOS}

Os estudos sobre redes de relação aumentaram exponencialmente nos últimos anos em diversas áreas do conhecimento como a antropologia, a sociologia e na pesquisa organizacional (BORGATTI; FOSTER, 2003). A grande expansão desse tipo de pesquisa fez emergir estudos com enfoque relacional sobre as redes de relação, ao contrário dos estudos com enfoque individual realizados anteriormente pela sociologia. Este enfoque relacional trata 
AS REDES DE CONTATOS PESSOAIS E AS PRÁTICAS DE INTELIGÊNCIA COMPETITIVA: UM ESTUDO SOBRE A ARQUITETURA DE RELACIONAMENTO EM UMA EMPRESA DE LOGÍSTICA

não apenas das relações isoladas entre os indivíduos membros de uma rede, mas também da estruturação e benefícios que estas redes trazem aos indivíduos e organizações.

Sob o enfoque da sociologia, a rede de relação pode ser definida como o conjunto das relações interpessoais que ocorrem entre dois indivíduos ou entre um grupo de indivíduos (IACOBUCCI, 1996). Já antropólogos sociais como Mitchell (1969, p. 69) desenvolveram o conceito de rede social para construir e explorar um entendimento sobre a "ação social e comportamento em termos das relações de partilha entre atores sociais".

No campo dos estudos organizacionais, esse conceito é ampliado para o ambiente empresarial e enfatiza as relações sociais que se vinculam e se sobrepõem ao indivíduo, grupos e organizações em conjunto. Nesse caso, os atores que fazem parte da organização ou que, de algum modo, participam dela têm posições e papéis definidos dentro das redes sociais e como conseqüência, suas interações acabaram influenciando o desenvolvimento dessa organização (MITCHELL, 1969).

Já no campo de estudos relacionados à Inteligência Competitiva, as redes sociais desempenham um fator importante no sentido de compensar habilidades ou capacidades que as organizações não possuem, além de expandir suas competências centrais a partir da coleta, distribuição e partilha de informações que serão transformadas em conhecimento que, se bem gerenciado, se tornará parte do ativo dessa organização (NOLAN, 1999).

Castells (1999) define a rede como estruturas abertas, compostas por um conjunto de nós interconectados que podem se expandir ilimitadamente, desde que esses nós consigam se comunicar dentro dessa rede. Para tanto, a rede necessita manter um código único de comunicação entendido por todos os nós da rede. Nesse contexto, a intensidade e freqüência da interação entre esses nós é que irá definir o tipo de estruturação de cada rede social.

$\mathrm{Na}$ literatura sobre redes, foram identificadas as redes interorganizacionais, as redes intraorganizacionais e as redes interpessoais como os três tipos de redes sociais existentes.

As redes organizacionais objetivam a partilha de contatos e obtenção de recursos (ALDRICH et al., 1987). Contudo, também se destacam estudos que enfatizam a interação entre membros de uma rede para diminuição de custos de produção e comercialização, bem como para a partilha de informações por meio de colaboração para desenvolvimento conjunto e transferência de tecnologia entre os membros dessa rede (BRITTO, 2002). Britto ainda destaca que as redes interorganizacionais podem se estruturar a partir de diversas organizações de um mesmo setor ou podem ocorrer por meio de interação com empresas integrantes de uma mesma cadeia. Já as redes intraorganizacionais são caracterizadas pela interação entre partes integrantes de uma mesma organização que podem ser caracterizadas por unidades ou pelos profissionais de uma organização (CUNHA, 2006).

Reconhece-se ainda a existência das redes interpessoais, caracterizadas pelas relações desenvolvidas pelos membros integrantes de uma mesma rede. Essas relações interpessoais podem ser concomitantemente interorganizacionais, intraorganizacionais e não se restringir aos membros da rede de sua organização e/ou unidade, sendo geralmente informais ao contrário das demais redes acima destacadas (CUNHA, 2006).

A literatura sobre redes já demonstra os benefícios que estas podem trazer as empresas. Dentre os benefícios destacados pelas redes pode-se citar a redução dos custos de produção e de transação, economias relativas à gestão da informação, ao seu uso e à 
aprendizagem (LUTHRA; DESOUZA, 2003), bem como facilitação da gestão da dependência de recursos e a considerável autonomia dada aos colaboradores dessas redes (PODOLNY; PAGE, 1998).

Essas redes propiciam a ativação e manutenção de canais de relacionamento que compensam as habilidades ou capacidades que as empresas não possuem internamente para, assim, expandir e tornar mais robustas suas próprias competências centrais com a finalidade de assegurarem a sua própria sobrevivência ou incrementar a sua competitividade (NOHRIA, 1992). Nesse contexto, torna-se claro que as redes contribuem indiretamente para fomentar a Inteligência Competitiva nas organizações.

\section{Inteligência Competitiva: origem, definições e propósitos}

A Inteligência Competitiva surgiu a partir da necessidade das empresas em se antecipar às mudanças ocorridas no mercado e em resposta ao ambiente tecnológico e globalizado (ABRAIC, 2008). Países como o Japão e Alemanha, França e Inglaterra (que estiveram envolvidos em guerras mundiais e em questões diplomáticas complexas) foram pioneiros em desenvolver a Inteligência Competitiva no mundo por se especializarem na coleta, processo, análise e uso da informação para fins estratégicos. Pelo fato da Inteligência estar ligado, na prática, à busca de informações de caráter confidencial é que a expressão, muitas vezes, é confundida com espionagem (FERNANDEZ, 2004). Entretanto, a Inteligência Competitiva aplicada nas empresas pressupõe o uso sistematizado de informações obtidas de forma ética e legalmente, relativas ao ambiente competitivo geral para a que a organização possa estabelecer tendências e cenários e possam responder mais rapidamente as alterações de mercado do que seus concorrentes (PRESCOTT; MILLER, 2002).

Várias conceituações já foram criadas para tratar de Inteligência Competitiva. Autores como Kahaner (1996) e Valentim et al. (2003) retratam a inteligência competitiva como um processo de investigação do ambiente no qual a empresa está inserida para descobrir oportunidades e reduzir os riscos. Para esses autores, o objetivo da Inteligência Competitiva está centrado no estabelecimento de estratégias de ação a curto, médio e longo prazo que suportem a construção de vantagens competitivas para as empresas.

Pozzebon et al. (1997) conceituam a inteligência competitiva como um sistema integrante da estrutura organizacional destinado a coletar e interpretar informações para garantir a competitividade da organização. Os autores tratam da IC como uma ferramenta para auxiliar a tomada de decisão organizacional. Nesse processo decisório, a IC faz o papel de catalisador da administração estratégica, sendo responsável por: planejar a utilização da informação estratégica; buscar o patrocínio dos decisores e a colaboração dos especialistas da organização; criar mecanismos de difusão da cultura estratégica e da inteligência na organização; coletar dados de forma eficaz, com filtros apropriados; organizar esses dados, transformando-os em informações relevantes, bem como analisar e validar essas informações relevantes; transformar as informações em inteligência; e disseminar os produtos de inteligência aos decisores e aos outros usuários de forma adequada.

Rodrigues; Riccardi (2007) ampliam o conceito de Inteligência Competitiva atribuindo-lhe as funções de um sistema pragmático de recoleção, análise e distribuição das informações relativas ao entorno competitivo da empresa e das tendências dos negócios. Para 
AS REDES DE CONTATOS PESSOAIS E AS PRÁTICAS DE INTELIGÊNCIA COMPETITIVA: UM ESTUDO SOBRE A ARQUITETURA DE RELACIONAMENTO EM UMA EMPRESA DE LOGÍSTICA

esses autores, a IC é um sistema corporativo que assegura as melhores decisões relativas ao desenvolvimento das capacidades internas e alocação de recursos, dando lógica, racionalidade e consistência aos objetivos da empresa. Ainda, a Inteligência Competitiva subsidia a identificação de tendências no ambiente dos negócios, isto é, a IC permite à empresa antecipar-se a possíveis mudanças de competição ou de consumo em seu mercado e, assim, assegurar maior eficiência das estratégias da empresa.

A partir das diversas conceituações apresentadas para tratar de IC, percebe-se que o termo apresenta pequenas diferenças conceituais pelos especialistas, especialmente devido às abordagens distintas de cada autor, talvez pelo fato de o corpo de conhecimento que se refere à Inteligência Competitiva seja ainda um tema emergente no ambiente acadêmico e de negócios. Contudo, apesar das diferenças apresentadas todos os conceitos apresentam alguns elementos essenciais comuns como, monitoramento ambiental e da concorrência, busca e disponibilização de informações para a tomada de decisões estratégicas das empresas (CARDOSO JUNIOR, 2003).

Tomando como ponto de partida as conceituações explicitadas sobre IC, o presente estudo se utilizará do enfoque apresentado por Rodrigues; Riccardi (2003; 2007) e Prescott; Miller (2002) para caracterizar a IC no ambiente empresarial. Um dos aspectos distintivos das funções da IC observado em Rodrigues; Riccardi (2007), assim como Teixera Filho (2000), refere-se ao fato da IC ser um mecanismo essencial ao processo de planejamento e transformação das informações coletadas e disponibilizadas, em conhecimento.

Como é comum em todos, também o processo da IC é constituído de várias fases que são descritas por Kahaner (1996) como planejamento e direcionamento, pesquisa e coleta de informações, análise e contextualização, disseminação e uso e gestão e avaliação. Para o autor, esse processo inicia na fase de planejamento e direcionamento do tipo de inteligência necessária para a organização, seguida de pesquisa e coleta de informações internas e externas a partir da determinação das informações necessárias, da identificação das fontes de informação e da coleta propriamente dita. A terceira fase do processo de IC é compreendida pela análise e contextualização das informações, ou seja, como essas informações são interpretadas, transformadas em conhecimento e inseridas no contexto do negócio da empresa para que diferentes cenários sobre essa mesma realidade sejam produzidos. As últimas etapas do processo de IC envolvem a disseminação e uso do produto da IC, onde ocorrem sugestões sobre possíveis ações a serem tomadas e a gestão e avaliação do produto da IC, onde todas as etapas inseridas nesse processo são avaliadas bem como os membros participantes desse processo. Entretanto, para que o programa de IC obtenha sucesso numa organização não basta que as pessoas participantes do processo cumpram suas tarefas. É necessário também que estas tenham envolvimento com todo o processo e que busquem constantemente informações estratégicas que sejam de interesse para o negócio da empresa. Outro fator a ser considerado para se implementar um programa de IC é não esperar que os resultados venham a curto prazo, pois processos que envolvam pessoas precisam de tempo para que as mesmas se qualifiquem para lidar e tratar com seus conteúdos e para criar redes que facilitem o fluxo dessas informações (FULD, 1995, PRESCOTT; MILLER, 2002).

\subsection{As redes de contatos pessoais e o processo de inteligência competitiva}


Autores ligados aos estudos organizacionais reconhecem os benefícios que as redes (tanto interorganizacionais quanto as intraorganizacionais e as de contato interpessoais) podem trazer às organizações. Foi apenas recentemente, no entanto, que os profissionais de Inteligência Competitiva reconheceram a importância das redes interpessoais para o negócio das empresas, especificamente, reconhecendo-as como veículos de coleta e disseminação eficiente de informações (PRESCOTT; MILLER, 2002).

Assim, as redes intrapessoais, ou redes de contatos pessoais são de extrema importância para fomentar o processo de IC, pois é através das redes de contatos que as informações são obtidas e que o conhecimento tácito, que é mais difícil de ser transmitido, acaba por se difundir na organização (APCQ, 1999). Além disso, são as redes de contatos pessoais que construirão a competência essencial de uma organização a partir do conjunto de habilidades pessoais de cada indivíduo integrante da organização (HAMEL; PRAHALAD, 1995). Nolan (1999) ainda destaca que as redes de contatos pessoais são muito eficazes para coletar informações de qualidade quando bem desenvolvidas. Essas redes de contato pessoais objetivam a interação entre pessoas que necessitam de informação com aquelas que detêm a informação e o conhecimento (CUNHA, 2006).

Para que essas redes de contato se desenvolvam, é necessário que os atores que interajem nessa rede se comuniquem. Olkkonen et al. (2000) descrevem a comunicação interpessoal como parte importante do processo de interação dos relacionamentos e das redes, pois estas só podem ser entendidas quando se considera o contexto e as características onde essa comunicação ocorre.

Segundo Nelson (1984) essas redes são compostas por atores que interagem entre si e dependendo do tipo de interação entre os atores envolvidos na rede elas podem ser classificadas como fortes ou fracas, formais ou informais, com caráter emocional forte ou podem ser utilizadas exclusivamente para ganhos comerciais e financeiros.

Prescott; Miller (2002) identificam dois tipos diferentes de redes de contato utilizadas para fomentar a IC nas organizações. As redes de coordenação rigorosa que concentram o desenvolvimento de relações estreitas e com alto nível de confianças com número limitado de pessoas e é utilizada em projetos complexos para a transferência de conhecimentos tácitos e as redes descentralizadas, utilizadas quando os usuários da IC possuem interesses diversificados, pois permite buscar rápida e amplamente informações e conhecimentos explícitos.

Os atores envolvidos nas redes de contatos pessoais possuem papéis definidos nessa rede. Awazu (2004) identifica cinco papéis informais adotados por atores em redes que podem ser identificados como conectores centrais, os especialistas, os porteiros, as pontes e os "boundary spanner". Conectores centrais são os atores que possuem contatos freqüentes dentro dessa rede e identificam a informação necessária para cada tipo de ator. São pessoas importantes na estrutura da rede de contatos pessoais. Os especialistas são profundos conhecedores de temas e produtos específicos, tendo sua experiência concentrada em determinada área. Os porteiros são aqueles atores responsáveis pela triagem, análise e atualização dos conhecimentos, enquanto as pontes são caracterizadas por atores extremamente comunicativos e conhecedores de produtos e serviços que colocam em contato 
AS REDES DE CONTATOS PESSOAIS E AS PRÁTICAS DE INTELIGÊNCIA COMPETITIVA: UM ESTUDO SOBRE A ARQUITETURA DE RELACIONAMENTO EM UMA EMPRESA DE LOGÍSTICA

pessoas de conhecimentos, habilidades e experiências diferenciadas. Já os "boundary spanner" são conectores de redes (que geralmente falam mais de um idioma) fora do seu ambiente conectam uma rede local com outras redes fora do seu ambiente. Buscam know how e têm acesso a uma variedade de conhecimento não restrito às suas habilidades profissionais e ao ambiente local.

A identificação dos papéis dos atores das redes e o tipo de rede utilizada pela empresa para fomentar as práticas de IC nas empresas é que definirá a arquitetura de relacionamento de uma empresa e vem a ser o objetivo central deste estudo.

\section{PROCEDIMENTOS METODOLÓGICOS}

A abordagem metodológica utilizada para o estudo do presente caso, um estudo de caráter descritivo e exploratório, pelo potencial de aprofundamento e contextualização que este tipo de método traz (PETTIGREW, 1992). Para Godoy (1995), uma pesquisa é descritiva quando os dados coletados são apresentados através de transcrições de entrevistas e anotações de campo, nunca sendo expressos de forma quantitativa ou numérica. Triviños (1995) define um estudo descritivo como sendo aquele que o pesquisador pretende conhecer uma comunidade, seus traços característicos, seus valores, etc. Para Godoy (1995), a opção pelo enfoque qualitativo torna-se mais apropriada em função da natureza do problema que se quer estudar e das questões e objetivos que orientam a investigação.

Uma das funções tradicionais dos estudos exploratórios é a identificação de necessidades de pesquisa. Para Selltiz et al. (1987) os estudos exploratórios são realizados quando o tema é ainda pouco explorado, quando não é possível fundamentar adequadamente hipóteses para a abordagem dedutiva e quantitativa com estudos prévios, quando é impossível uma revisão de pesquisas precedentes já avançadas, quando ainda não há conhecimentos já bem estabelecidos sobre o tema abordado e quando é necessário fazer levantamentos junto a pessoas que tiveram experiência prática com o problema estudado para seu esclarecimento e delimitação.

A escolha da ATT como objeto do presente estudo deve-se principalmente ao pioneirismo desta empresa no transporte modal no Brasil e à posição de destaque que ocupa, por ser correntemente a maior empresa de transportes multimodal do estado do Paraná. A TT foi pioneira, em 1981, ao iniciar a logística multimodal por meio de seu terminal capaz de operar cargas agrícolas a granel. Desde então a empresa tem movimentado 21 milhões de toneladas, mantendo-se como a maior empresa nesta área. Para gerenciar as atividades multimodais, no entanto, a ATT precisa administrar com extrema eficiência um sistema de informações especializado, com informações de várias bases cognitivas, em logística, tempos, sincronias de recepção, armazenagem e transportes de cargas,características de transportadoras intermediárias e finais e outras. Estando assim, no centro de um processo que envolve dezenas de players, precisa visualizar o movimento para garantir a eficiência de toda a cadeia na qual se insere. A sustentação dessa estratégia é sua inteligência de negócios, que aqui se constitui num frutífero campo de investigação.

Para a coleta de dados utilizou-se na coleta de dados primários, uma entrevista semiestruturada, com quatro sujeitos sociais. Foram escolhidos dois informantes-chave da diretoria 
da ATT, por estarem vinculados à empresa desde sua criação (chefe de operações logísticas e o diretor comercial da empresa). Os outros dois informantes pertencem à base operacional da empresa e constituem porta de entrada da maioria das informações que transitam vertical ou horizontalmente. Além dessas fontes, forma utilizadas outras fontes de várias origens, como documentos oficiais e relatórios formais da empresa, tais como atas de reuniões, trabalhos acadêmicos realizados sobre a empresa, informações sobre o histórico da empresa divulgada através do seu site, leis e decretos relacionados ao setor de logística, entre outros.

As respostas gravadas das entrevistas foram transcritas para análise de conteúdo. Bardin (1982) indica que esse tipo de análise consiste na interpretação dos dados a partir da análise léxica, ou análise de conteúdo. Uma análise de conteúdo é basicamente de caráter qualitativo. Nela, os dados são avaliados dentro do contexto pesquisado, onde expressões escritas e verbais são analisadas com o objetivo principal de se entender o fenômeno estudado. As informações de conteúdo foram complementadas por informações documentais de modo a enriquecer e esclarecer as interpretações das informações analisadas.

Para estabelecimento de validade do "constructo e confiabilidade" do estudo de caso apresentado, os dados foram tratados e comparados, devido à utilização de várias fontes de coleta de dados, de forma a produzir uma triangulação dos dados, "fundamento lógico para se utilizar várias fontes de evidências" (YIN, 2005, p. 120).

\section{ATT TRANSBORDO: CARACTERIZAÇÃO DA EMPRESA, REDES SOCIAIS E SUAS PRÁTICAS DE INTELIGÊNCIA COMPETITIVA}

\section{Histórico da ATT}

A ATT foi fundada em 1981, na cidade de Londrina, Paraná, como uma empresa de armazéns gerais, associada à Rede Ferroviária Federal S/A (RFFSA), mercado no qual atuou até 1989. A RFFSA, como uma empresa estatal monopolista no mercado de transporte ferroviário brasileiro, possuía exclusividade no transporte de combustíveis, do trigo e do minério de ferro. Esses produtos sustentavam razoavelmente a estrutura da companhia, o que não a encorajava a garimpar novas oportunidades de negócios. Por tradição, a RFFSA somente transportava produtos de clientes que estivessem instalados sobre trilhos, ou seja, cujas unidades produtores possuíssem desvio ferroviário que permitisse o carregamento dos vagões nas próprias unidades dos clientes.

Em 1989, no entanto, o gerente comercial da RFFSA procurou a diretoria da ATT interessado em viabilizar o transporte multimodal do farelo de soja, produzido por uma indústria de esmagação de grãos, no interior de São Paulo. Essa era uma idéia absolutamente inovadora no Brasil, embora fosse algo já corriqueiro no resto do mundo há muito tempo.

A idéia do gerente comercial da RFFSA prosperou e encontrou acolhida junto à diretoria da ATT, que visualizou a oportunidade como uma forma de diversificar seu portifólio de serviços e de sua base de clientes. A unidade de Londrina era propícia para os fins desejados, pois possuía desvio ferroviário e investimentos foram feitos para adaptar a unidade armazenadora de então, tornando-a uma unidade transbordadora. Além disso, Londrina está posicionada em um extremo da malha ferroviária do sul do Brasil e liga-se aos 
AS REDES DE CONTATOS PESSOAIS E AS PRÁTICAS DE INTELIGÊNCIA COMPETITIVA: UM ESTUDO SOBRE A ARQUITETURA DE RELACIONAMENTO EM UMA EMPRESA DE LOGÍSTICA

portos de Paranaguá/PR e São Francisco do Sul/SC. O primeiro deles, à época, era o principal porto graneleiro de exportação brasileiro.

Como todo novo empreendimento, porém, para viabilizar o transbordo foi necessário construir uma infra-estrutura adaptada aos processos de carga e descarga, a partir do zero: desde selecionar e determinar as características dos equipamentos de movimentação e seu posicionamento no terminal; criar sistemas de controle e informação; achar soluções para movimentação dos vagões dentro do terminal; solucionar problemas com a movimentação da documentação fiscal, etc. Já existiam no Brasil outros terminais multimodais, mas eles movimentavam apenas cargas unitizadas, como contêineres e mercadoria industrializada. A ATT iria movimentar carga agrícola a granel, cujo controle e auditoria de estoques requeria sistemas de informações diferentes.

Em 1996 a ATT venceu uma concorrência e passou a administrar um pequeno terminal de transbordo, de propriedade da RFFSA, que havia sido construído em Maringá/PR. A ATT então adaptou as instalações de um pátio de movimentação de materiais anteriormente usado para a construção da Itaipu e que naquele momento se encontrava abandonado, desde o final das obras da hidrelétrica.

Seu excelente trabalho como gerenciadora de transbordos de à ATT uma imagem de seriedade, competência e qualidade de serviços, consolidando-a nesse segmento de mercado. Isso mereceu à ATT, em 1998, a indicação, por um de seus clientes, uma grande multinacional do setor de commodities agrícolas, para assessoria técnica à Ferronorte S/A no projeto e construção de dois terminais de transbordo a serem instalados nas cidades de Chapadão do Sul/MS e Alto Taquari/MT. Naquele ano, a Ferronorte estava concluindo o novo trecho ferroviário que ligava Aparecida do Taboado/MS a Alto Taquari/MT. Este braço ferroviário conecta-se ao Porto de Santos/SP através da malha da antiga Ferroban. A assessoria da ATT à Ferronorte resultou na construção dos terminais em tempo recorde e com um custo inferior ao inicialmente projetado nos orçamentos da Ferronorte. Por essa razão, a Ferronorte convidou a ATT a operar, sob contrato de terceirização, os terminais recentemente concluídos.

Também na malha sul os negócios se expandiam. Em 2000 o terminal de Maringá/PR recebeu investimentos por parte da ferrovia, visando a ampliação de sua capacidade instalada. Para estes investimentos também foram contratados os serviços de consultoria da ATT. Em 2001 a ATT gerenciava quatro terminais multimodais de granéis agrícolas, que possuíam uma das maiores capacidades de movimentação em transbordo de produtos do país.

\section{O Setor Logístico da ATT}

A ATT está inserida numa longa cadeia logística que inicia no produtor agrícola e termina no terminal portuário. A quase totalidade da demanda do serviço de transbordo de granéis agrícolas é para produtos destinados à exportação. Entretanto, também é possível fazer o transbordo no sentido contrário, ou seja, na cadeia que inicia no terminal portuário e termina no produtor ou no moinho de trigo. Esta cadeia logística inversa movimenta fertilizantes de trigo, que são majoritariamente importados no Brasil. 
Até a privatização todos os elos da cadeia logística eram pulverizados entre vários competidores e, portanto, seus elementos não eram capazes de exercer poder relevante no ambiente da competição de transportes de grãos.

Nos anos 80 e 90 a fronteira agrícola brasileira expandiu-se em direção aos cerrados do Centro-Oeste. Aí, a produção agrícola não encontrava infra-estrutura logística capaz de movimentá-la eficientemente até os centros atacadistas ou de distribuição para consumo interno e embarque para exportação. Assim, até a década de 90 quase toda a produção era transportada através de caminhões, de ponta a ponta, num conceito único, onerando a logística de grãos, pelo tipo de transporte utilizado. Como o Brasil tradicionalmente produz excedentes agrícolas, boa parte da produção primária e da beneficiada, tem sido direcionada à exportação. O caso ilustrativo mais típico é o complexo soja, composto da soja em grão e dos beneficiados farelo e óleo de soja. Como há limitação nos processos de embarque e interesse no custo da logística, diferentes portos devem ser utilizados, eventualmente aumentando a ineficiência dos processos tradicionais de transporte. Por exemplo, a produção dos Estados de Goiás e Minas Gerais escoa através do porto de Santos/SP, mas a produção de Mato Grosso do Sul e do Mato Grosso é exportada através do porto de Paranaguá/PR.

Genericamente, pode-se categorizar a cadeia logística de exportação nos seguintes agentes e interventores na cadeia: Agricultores - são os responsáveis pela produção agrícola como um todo.

Empresas comercializadoras, embarcadores ou traders - são o segundo elo da cadeia logística. Eles adquirem a produção do agricultor e movimentam o produto até seu destino final. Até 1989, os comercializadores só possuíam duas opções logísticas: transporte rodoviário ou ferroviário em cadeia única. Com o surgimento da ATT, criou-se pela primeira vez a possibilidade de utilização do transporte multimodal na agricultura (rodoviário + ferroviário).

Transportadores rodoviários - extremamente pulverizadas e operando em regime de concorrência feroz, estas empresas são responsáveis por coletar a mercadoria na sua origem levando-a via rodoviária até seu destino, que pode ser um consumidor final (fábrica), um terminal de transbordo ou um terminal portuário.

Terminal de transbordo - são terminais multimodais capazes de transferir rapidamente a carga de um modal de transporte para outro. Normalmente possuem capacidade de armazenagem de maneira a facilitar o gerenciamento dos diferentes fluxos de mercadoria.

Transportador ferroviário - é a empresa responsável pela movimentação da mercadoria sobre trilhos.

Terminais portuários - também altamente regulados pelo poder público, têm a função de receber os produtos via rodoviária ou ferroviária e armazená-los até a atracagem dos navios que os levarão até seu destino final.

$\mathrm{Na}$ cadeia logística de importação, os embarcadores são substituídos pelos importadores de fertilizantes e grãos suplementares (grãos em que o país não é autosuficiente, como trigo e outros). Este elo da cadeia também passou por forte concentração e desnacionalização recentemente, sendo hoje dominado pelos grandes players mundiais. No caso da importação de trigo, os embarcadores são normalmente os próprios moinhos que, 
AS REDES DE CONTATOS PESSOAIS E AS PRÁTICAS DE INTELIGÊNCIA COMPETITIVA: UM ESTUDO SOBRE A ARQUITETURA DE RELACIONAMENTO EM UMA EMPRESA DE LOGÍSTICA

portanto, também são o destino final do produto. Outros produtos também podem utilizar esta cadeia logística, mas não possuem importância em termos de volume.

\section{Alterações nos aspectos normativos do setor - a privatização}

Na década de 90 o Brasil passou por profundas mudanças econômicas. Em 1993 foi lançado o plano Real que conseguiu eliminar o então considerado problema número 1 do país: a inflação. Outro debate muito importante nos meios econômicos da época era sobre a quebra dos grandes monopólios estatais, conforme estatuído em nossa constituição. O monopólio do transporte ferroviário, gerenciado pela RFFSA, também fazia parte desta discussão e o setor foi incluído no Plano Nacional de Desestatização. A malha ferroviária nacional foi subdividida em seis malhas regionais e a malha sul que abrangia os estados do Rio Grande do Sul, Santa Catarina e Paraná foi leiloada no final de 1996. Em $1^{\circ}$ de março de 1997 a empresa vencedora assumiu o gerenciamento desta malha. Chamada inicialmente de Ferrovia SulAtlântico S/A (FSA), a empresa era controlada por alguns fundos de investimentos nacionais e alguns investidores estrangeiros. Estes controladores compuseram a primeira diretoria da empresa com uma mescla de profissionais com alguma experiência em ferrovias e uma grande maioria de executivos com origens no mercado financeiro. A primeira decisão tomada por este corpo diretivo foi a demissão de $50 \%$ do quadro funcional existente até então. Embora estas decisões fossem esperadas, a forma de implantação e a rapidez com que foram implementadas causaram certa surpresa, conforme relata um dos informantes.

As mudanças não se resumiram ao campo dos recursos humanos. Muitos investimentos foram feitos na recuperação do material rodante - vagões e locomotivas - e da infra-estrutura - trilhos. Também foi implantado um novo modelo de gestão, baseado no modelo encontrado comumente no mercado financeiro que se baseava em forte cobrança de resultados ambiciosos atrelados a recompensas financeiras aos que os atingissem.

\section{Fatores e práticas comerciais do negócio da ATT}

Alguns fatores, como produtos, clientes e infra-estrutura, bem como as formas das práticas comerciais realizadas pela ATT, em seu início e depois da privatização condicionaram a formação e a estrutura das redes sociais da empresa. Isso, certamente, tem orientado o perfil e a dinâmica de funcionamento das redes nas operações da empresa. Para entender-se as redes e seu papel como canais ou sistema de inteligência competitiva é importante antes compreender seu funcionamento.

A) Produtos

A ATT é uma empresa fornecedora de serviços logísticos para os participantes da cadeia de movimentação de produtos agrícolas. Seu foco sempre foi no manuseio de granéis agrícolas como soja, milho, trigo, sorgo, cevada, farelo de soja, farelo de algodão, açúcar, fertilizantes, óleo vegetal, etc. Entretanto, sempre que solicitada nunca deixou de oferecer alguma alternativa de solução para manusear outros tipos de produtos, como por exemplo: 
pneus, ferro-gusa, perfis metálicos, insumos para café solúvel, adubo ensacado, adubo em bigbag, etc. Os serviços que a ATT oferece a seus clientes são basicamente dois:

1) Armazenagem: consiste em receber os produtos dos clientes e acondicioná-los em ambiente adequado e protegido, de maneira que, ao retirá-lo, o cliente o encontre na mesma quantidade e qualidade.

2) Transbordo: consiste na movimentação da carga entre dois modais de transporte distintos. Engloba a descarga do produto, armazenagem e recarga do mesmo. Pode ser feito diretamente entre um veículo e outro ou necessitar que o produto seja armazenado durante pequeno espaço de tempo, até que o modal de destino esteja disponível. Este tipo de armazenagem é chamada armazenagem-pulmão.

\section{B) Clientes}

A ATT é claramente um negócio business to business (B2B), e seus clientes, além de poucos, são grandes empresas nacionais e internacionais. A ATT fornece um tipo de serviço onde a escala é fundamental para viabilizar economicamente a operação e, portanto, não é viável trabalhar com clientes com pequenos lotes. Pelo seu tamanho e profissionalismo, esses clientes são muito difíceis de lidar no processo de negociação. Usam constantemente a barganha para conseguir alguma vantagem adicional e não raro utilizam seu volume de transação e tamanho econômico para imposições a ganhos e ameaças comerciais.

Inicialmente o pioneirismo e a inovação trazidos pela ATT a protegeram nesse embate, porém, à medida que o mercado foi criando alternativas, as negociações passaram a ser mais duras. Como reação, a ATT passou a concentrar-se na qualidade de seus serviços, na garantia de integridade do produto manuseado, no sistema de informações e controle que a empresa desenvolveu para gerir seus negócios. O controle e o sistema de informações da ATT permitiam aos clientes acessarem informações precisas e atualizadas, em tempo real, sobre suas operações. Entretanto, somente essas qualidades não garantiam poder de barganha suficiente para determinar o preço de seus serviços e preço, de fato, nunca deixou de possuir papel central nas negociações, o que passou a pressionar as margens da ATT, com o passar do tempo.

\section{C) Ferrovia}

A ferrovia exerce um papel fundamental na formatação do negócio da ATT. Como administradora de terminais multimodais, os serviços da empresa conectam a ferrovia à rodovia. O transporte rodoviário é extremamente pulverizado no Brasil e não representa risco maior ao negócio da ATT. Embora as transportadoras também possam ser consideradas concorrentes ao oferecer a alternativa de transporte direto até o destino, enquanto houver as diferentes modalidades de transporte, haverá sempre um espaço para os serviços intermodais.

Tradicionalmente, as transportadoras tem sido vistas como aliadas e parceiras pela diretoria da ATT, para consolidar e expandir seu negócio. Já o transporte ferroviário sempre foi um risco, considerado de importância estratégica para o negócio da ATT. Pelo sistema monopolista de gestão ferroviária existente no país, apenas uma ferrovia pode atender a um terminal da ATT. Se esta empresa falha, operacional ou comercialmente, a ATT não possui alternativa para prestar seus serviços de transbordo. Isto sempre foi visto de uma forma 
AS REDES DE CONTATOS PESSOAIS E AS PRÁTICAS DE INTELIGÊNCIA COMPETITIVA: UM ESTUDO SOBRE A ARQUITETURA DE RELACIONAMENTO EM UMA EMPRESA DE LOGÍSTICA

fatalística pela direção da empresa que, entretanto, até este momento nunca havia se preocupado seriamente com o problema. A privatização e a mudança de gestão radical das ferrovias, especialmente a ocorrida na concessionária da ferrovia onde a ATT opera, portanto, representam um marco importantíssimo nas operações dessa empresa. Há dois momentos distintos para a forma de operação da ATT, antes e depois da privatização.

D) Práticas comerciais pré-privatização

Este foi um período singular nas atividades da ATT. A direção da empresa concentrou-se no desbravamento e criação de um mercado que ainda não existia. Neste período, a empresa funcionava como um braço comercial da RFFSA, pois a mesma não possuía recursos para implementar ações mercadológicas, fora de sua alçada legal.

Entretanto, como todo produto inovador, o transporte intermodal de granéis agrícolas como oferecido pela ATT era visto com resistência pelos embarcadores. Eles receavam perder o controle sobre os volumes transportados uma vez que o produto estava a granel. O primeiro cliente após a operação pioneira que formatou o negócio só foi conseguido após três viagens do diretor comercial da ATT, ao Centro-Oeste brasileiro. A fronteira agrícola se expandia rapidamente nesta região e várias fábricas de esmagamento de soja se instalaram em Campo Grande/MS, Rondonópolis/MT e Cuiabá/MT, na virada da década de 1980-90. Estes foram definidos como os clientes preferenciais da ATT no início, pois apresentavam uma possibilidade de utilização dos serviços de forma mais perene - as fábricas funcionavam normalmente 10 meses por ano - e sua produção era quase totalmente destinada à exportação.

Nesta época a ATT, em função de seu posicionamento na cadeia logística, de seu acesso às informações e de suas boas relações com a RFFSA, era vista pelos embarcadores como uma facilitadora. Todos recorriam a ela para solucionar problemas eventuais, mesmo que este problema não fosse de sua alçada ou responsabilidade.

Durante este período um dos entrevistados relata que a empresa faturava a totalidade de seus serviços contra os embarcadores toda a semana, com um prazo médio de recebimento de 7 dias. Os embarcadores contratavam diretamente o transporte rodoviário e ferroviário com as transportadoras e junto à RFFSA.

E) Práticas comerciais pós-privatização

A privatização alterou completamente o quadro apresentado anteriormente. Assim que a nova empresa, a FSA, assumiu o controle da concessão em março de 1997, as relações comerciais vigentes na cadeia começaram se alterar. A FSA, depois rebatizada de ALL América Latina Logística exigia absoluto controle sobre a utilização de seus serviços. Imediatamente foi solicitado à ATT que ela não mais abordasse os clientes da ferrovia e que ela devia ater-se apenas aos seus serviços. Além disso, a ALL reivindicava o direito de indicar aos embarcadores o local onde a carga deveria ser transbordada. Isto diminuía consideravelmente o poder da ATT dentro da cadeia logística. Um dos informantes-chave descreve a situação da seguinte maneira:

“A gente não gostou disso e até resistiu um pouco, mas não queríamos criar atritos logo no início com os novos controladores da ferrovia. Além disso, o discurso deles ainda era amigável. Falavam muito de parcerias e novos negócios. 
Só que ficava bem claro que eles queriam controlar tudo e obviamente ficar com a parte do leão."

Com quadros muito mais profissionais e com a implantação do novo modelo de gestão, a ferrovia passou a posicionar-se como uma empresa de logística. Isto ficou claro ao mundo exterior quando a empresa alterou sua denominação social passando a chamar-se ALL - América Latina Logística S/A. A ALL interessava-se em participar de toda a logística de seus clientes. Lançou um braço de transporte rodoviário que visava abastecer seus trens de carga e até mesmo atender clientes puramente rodoviários, concorrendo com as transportadoras estabelecidas. Também criaram uma direção de terminais com o objetivo de gerenciar terminais de carga e incentivar o investimento de terceiros ao longo de sua malha de trilhos. Também interessaram-se em participar do investimento em terminais portuários de maneira a agilizar a descarga de seus vagões.

Outra mudança relevante que também afetava a ATT era a tentativa da ALL em diversificar os produtos transportados. Fortemente concentrada em produtos agrícolas, a ferrovia, na época da privatização, possuía uma receita muito sazonal e que acompanhava o calendário e o tamanho das safras. Embora a ALL não se descuidasse do segmento agrícola, ela procurou diversificar seus investimentos na busca de novos clientes, com novos produtos. Foram intensificados esforços para aumentar o transporte de produtos industrializados que apresentavam volumes mais perenes e melhores margens de retorno nos fretes. Para a ATT, a situação parecia deteriorar-se, como analisa o entrevistado da diretoria da ATT.

"Parecia que eles não estavam nem aí conosco. Embora ainda gerássemos uma parte enorme de seu faturamento, éramos tratados como o patinho feio do negócio. Os trens se atrasavam porque a prioridade era dos industriais. As programações mudavam de uma hora para outra, apenas em função dos interesses deles. A coisa tava ficando dificil. Como manter a qualidade para o cliente neste ambiente? Volta e meia tínhamos problemas de estadias de caminhões em nossos pátios que causavam enorme prejuizo aos nossos clientes e a ALL não parecia importar-se com isso."

De todas a pressões que sofria a ATT, a pior delas, sem dúvida, era a sensação de desimportância que passava a apoderar-se da direção da ATT. De elemento importante e influente num modelo de negócio, a ATT estava se tornando apenas mais uma peça da cadeia e o seu serviço passava a ser visto como uma commodity desimportante. $\mathrm{O}$ segundo entrevistado da diretoria da ATT descreve bem o momento quando se expressa:

“As coisas estavam piorando. Viamos nossos clientes sendo direcionados a outros terminais. Víamos a ferrovia oferecer outras opções que nos excluíam. Diziam que queriam parceria, mas nos tratavam como inimigos. O discurso era um, mas a prática era outra. Eles só queriam saber de dinheiro, não interessava quem pagasse a conta e muito menos como."

Para piorar a situação, a ALL passou a exigir que seus clientes a contratassem para fazer o serviço door-to-door. Neste modelo, a ALL é que escolhia e contratava os transportadores rodoviários e os terminais.

A ALL exigia prazos de pagamentos maiores que os embarcadores, elevando o prazo médio de recebimento da ATT de 7 para 35 dias. Além disso, o faturamento da ATT estava 
AS REDES DE CONTATOS PESSOAIS E AS PRÁTICAS DE INTELIGÊNCIA COMPETITIVA: UM ESTUDO SOBRE A ARQUITETURA DE RELACIONAMENTO EM UMA EMPRESA DE LOGÍSTICA

ficando concentrado em apenas um pagador. Qualquer tropeço burocrático, intencional ou não, causava grandes alterações no fluxo de caixa da ATT. Os riscos estratégicos também estavam crescendo. A ATT estava perdendo completamente o gerenciamento de sua receita. Não havia esforços que a diretoria pudesse fazer para alterá-lo. Sua única alternativa era gerir os custos para manter sua margem. Nos últimos 24 meses a diretoria da ATT, buscando reverter a situação voltou novamente a prospectar clientes a fim de diversificar sua carteira de clientes. O transbordo de novos produtos, como por exemplo o álcool, poderia ser sua saída.

\section{Práticas de IC e suas conexões com as Redes Sociais}

As práticas de IC podem ser observadas no presente caso em diferentes momentos organizacionais da ATT. Desde o período anterior à privatização do setor ferroviário até o término deste processo, onde a empresa atuava de diferentes maneiras no processo de monitoramento organizacional, um dos elementos das práticas de IC. Tal aspecto é confirmado por Passos (2005) ao afirmar que a IC é o processo de monitorar o ambiente competitivo permitindo aos profissionais de empresas a tomar decisões atualizadas sobre o ambiente externo e interno de uma organização, independente do seu porte. $\mathrm{O}$ autor cita também que IC permite a organização a tomar decisões referente aos processos de pesquisa, desenvolvimento e comercialização, com o objetivo de definir a estratégia empresarial a longo prazo. IC é um processo efetivo e contínuo de informação. Complementarmente tem-se ainda reafirmados os dizeres de Marcial (1999) e Rodrigues; Riccardi (2007) quando os mesmos relatam que a IC é um excelente instrumento de produção de informação estratégica para a definição das estratégias competitivas da organização.

Outro aspecto observado na ATT refere-se às questões relativas à interação social dos atores também destacadas por Prescott (2002). Em muito dos relatos dos informantes fica evidente que tanto internamente quanto externamente a formação de redes de contato possui significativa importância para o desenvolvimento do negócio. Nolan (1999) relata que as redes sociais desempenham um papel importante no sentido de compensar habilidades ou capacidades que as organizações não possuem, além de expandir suas competências centrais a partir da coleta, distribuição e partilha de informações que serão transformadas em conhecimento que, se bem gerenciado, se tornará parte do ativo dessa organização. Já para Britto (2002) há interação entre os membros de uma rede para diminuição de custos de produção e comercialização, bem como para a partilha de informações por meio de colaboração para desenvolvimento conjunto e transferência de tecnologia entre os membros dessa rede (BRITTO, 2002; LUTHRA; DESOUZA, 2003).

Internamente a prática de comunicação da empresa parecia garantir que as informações sejam disponibilizadas integralmente para todos os membros da diretoria e os responsáveis pela operação logística. Tal prática se mostrava importante para assegurar o alinhamento dos processos com o discurso incorporado na política de qualidade das operações comerciais e operacionais (por exemplo, prazos de carregamento de cargas, etc). Para tanto, a empresa tinha como prática, certificar-se da proximidade física (todos alocados na mesma sala) e da replicação de mails para os diretores e operadores logísticos. Ressalte-se que tal prática somente é possível por haver relativa concentração de clientes. 
Externamente, observa-se que muitas informações essenciais do negócio eram transmitidas via tais interações sociais. Informações sobre quem irá utilizar os terminais do porto, quando e como as mercadorias seriam transportadas (início do processo comercial da ATT), eram conseguidas via "conhecidos". Tais informações não garantiam o fechamento de negociação, porém, cientificavam a empresa sobre os clientes e cargas que poderiam ser transbordados. Os entrevistados destacaram ainda que para o negócio funcionar era necessário construir uma rede de relacionamento com vários especialistas internos da ATT, junto aos principais clientes. Tal prática facilita os processos de negócio da ATT.

Neste caso, tem-se a descrição de uma rede intra-organizacional, já descrita por Cunha (2006). Tais redes são caracterizadas pela interação entre membros integrantes de um setor numa mesma organização. Esses conjuntos internos que podem ser caracterizadas por unidades ou por grupos de profissionais de uma organização.

Além da formação da rede intra-organizacional, observou-se ainda a formação de redes interpessoais, onde houve uma expansão das relações desenvolvidas pelos membros integrantes de uma mesma rede (intra-organizacional), que a priori tinha objetivos comerciais e que com o tempo acabaram se estendendo para captação e troca de informações de outra natureza, não necessariamente afetas ao negócios, mas com decisiva influência sobre as negociações. Tal aspecto tem ainda junto a literatura de IC significativo destaque, ao serm reconhecidos os benefícios que as redes (tanto interorganizacionais quanto as intraorganizacionais e as de contato interpessoais) podem, de forma complementar, trazer às organizações (PRESCOTT; MILLER, 2002).

No que tange aos aspectos mencionados acima, Nolan (1999) destaca que as redes de contatos pessoais são muito eficazes para coletar informações de qualidade quando bem desenvolvidas. Essas redes de contato pessoais objetivam a interação entre pessoas e podem ser utilizadas para a aprendizagem, ou confirmação de veracidade das informações, entre as pessoas que necessitam de informação com aquelas que detém o conhecimento (CUNHA, 2006).

\section{CONSIDERAÇÕES FINAIS}

O presente artigo buscou analisar como as redes de contatos sociais são utilizadas para fomentar as práticas de IC, num caso selecionado, uma empresa de transbordo, a ATT. Em relação às práticas de $\mathrm{IC}$, desenvolvidas pela $\mathrm{ATT}$, observaram-se diferentes práxis ao longo do período de atividade da empresa analisada. As práxis de IC iniciaram-se na fase anterior à privatização do setor ferroviário e tornaram-se vitais no período posterior. $\mathrm{Na}$ fase anterior, a empresa atuava de forma incipiente e pouco organizada, no processo de monitoramento de seu ambiente competitivo, já que possuía uma posição privilegiada nos processos de transbordo durante o período de monopólio estatal nos transportes ferroviários. Tais processos de prática inicial de IC estão bem descritos por Passos (2005).

Na segunda fase, pós-privatização da rede ferroviária federal, o papel e função da IC na ATT estão melhor descritos por Rodrigues; Riccardi (2007), que ampliam a visão de Passos, afirmando que a IC é um excelente instrumento de produção de informação estratégica para a formulação de estratégias corporativas e competitivas da organização. Esse 
AS REDES DE CONTATOS PESSOAIS E AS PRÁTICAS DE INTELIGÊNCIA COMPETITIVA: UM ESTUDO SOBRE A ARQUITETURA DE RELACIONAMENTO EM UMA EMPRESA DE LOGÍSTICA

foi o caso da ATT, que após a privatização do setor, passou a ser fortemente pressionada pela nova direção da FSA, ávida por controlar todas as fases da cadeia logística de produção agroindustrial. Somente informações privilegiadas, que seriam transformadas em estratégias competitivas eficientes, de novos clientes e produtos agrícolas alternativos a granel em larga, poderiam salvar o negócio da ATT.

Observa-se no caso da ATT que a interação social, não apenas informativa, dos atores também destacadas por Prescott; Miller (2002), constituiu fator essencial para o negócio da ATT. Em muito dos relatos dos entrevistados, fica evidente que, tanto internamente quanto externamente, a formação de redes sociais tem sido fundamental para os negócios da ATT, pois é a partir da mesma que a empresa passa a ter a informação para a negociação e o fechamento de contratos de transbordo.

As redes sociais são apontadas por Nolan (1999) como importante fator no sentido de compensar habilidades ou capacidades que as organizações não possuem, além de expandir suas competências centrais a partir da coleta, distribuição e partilha de informações que serão transformadas em conhecimento que, se bem gerenciado, pode tornar-se parte do ativo dessa organização. Britto (2002), e Luthra; Desouza (2003) corroboram as observações de Nolan e complementam que a interação entre membros de uma rede propicia ainda a diminuição de custos de produção e comercialização.

A práxis interna da ATT decorre da política de comunicação da empresa, segundo a qual todas as informações devem ser disponibilizadas integralmente para os membros da diretoria e para os operadores logísticos. Essa prática na ATT tem se mostrado bastante alinhada com o "discurso" da alta diretoria, para garantir o bom desempenho da empresa nos aspectos operacionais e comerciais (como por exemplo, prazos de carregamento de cargas, etc). Tal prática pode ser observada pela proximidade física dos funcionários (todos alocados na mesma sala) e na replicação de mails para os diretores e operadores logísticos.

Externamente pode-se observar que muitas informações essenciais ao negócio são transmitidas via interações sociais entre os indivíduos pertencentes à rede. Informações sobre quem (clientes) precisa utilizar os terminais do porto, quando e como transportará as mercadorias são conseguidas via "conhecidos" (indivíduos da rede),em grande parte das vezes de maneira informal, por ocasião das socializações. Tais informações são o início do processo comercial da ATT. Não garantem o fechamento de negociações e contratos, mas ao cientificar a ATT sobre clientes e cargas que poderão ser transbordados, aumentam tremendamente as chances de fechamento de serviços.

Para que o processo funcione, os entrevistados destacaram ainda que é necessário também construir uma rede de relacionamento junto aos principais clientes, com informações de conteúdo específicos. Essa prática está descrita nas redes intraorganizacionais de Cunha (2006), que são caracterizadas pela interação entre indivíduos de uma mesma organização, responsáveis por um conjunto de informações funcionais ou profissionais, que funcionam como especialistas para uma determinada área da empresa. No presente caso, além dessas, observou-se a formação de redes interpessoais adicionais, representando uma expansão das relações desenvolvidas pelos membros da rede intra-organizacional. As redes interpessoais externas funcionavam sempre como canais de informação adicional, por vezes confirmatórios, 
por vezes suplementar, por meio das portas de entrada (especialistas internos) das redes intraorganizacionais.

Esse conjunto de sistemas de coleta e disseminação da informação, ainda que inicialmente de caráter informal, tem merecido destaque na literatura especializada (PRESCOTT; MILLER, 2002) por causa de suas vantagens em termos de custo, de rapidez de acesso à informação e de facilidade de disseminação da mesma aos tomadores de decisão na organização. Tal fator também foi discutido por Nolan (1999) e Cunha (2006) ao destacarem que as redes de contatos pessoais, quando bem desenvolvidas, são muito eficazes para coletar informações de qualidade e dar apoio aos processos decisórios.

Desta forma, no caso estudado, as redes sociais (intra, inter-organizacionais e interpessoais) tem desempenhado papel primordial para o bom desempenho dos negócios na ATT, demonstrando que tais práticas já estão sedimentadas e são operacionalizadas de maneira sistemática na empresa.

\section{REFERÊNCIAS}

ABRAIC. Associação Brasileira de Inteligência Competitiva. Disponível em: $<$ http://www.abraic.org.br/v2/>. Acesso em: 10 jul. 2008.

ALDRICH, H. The Impact of Social Networks on Business Founding and Profit: A Longitudinal Study. In: (Eds) Frontiers of Entrepreneurship Research, Wellesley, Mass: Babson College, 1987.

APQC. Starting a CI Program Houston: APQC. 1999. Disponível em: <www.apqc.org>. Acesso em: 10 jul. 2008.

AWAZU, Yukika. Informal roles and intelligence activities: some management propositions. Journal of Competitive Intelligence and Management. v. 2, n. 1, p. 16-24, Spring 2004.

BORGATTI, Stephen; FOSTER, Pacey. The network paradigm in organizational research: a review and typology. Journal of Management, v. 29, n.6, p. 991-1013, 2003.

BRITTO, J. Cooperação interindustrial e redes de empresas. In: KUPFER, D. e HASENCLEVER, L. (Org.) Economia Industrial. Rio de Janeiro: Campus Elsevier, 2002.

CARDOSO JUNIOR, W. F. A inteligência competitiva aplicada nas organizações do conhecimento como modelo de inteligência empresarial estratégica para implementação e gestão de novos negócios. 2003. 209 f. Tese (Doutorado em Engenharia de Produção) Universidade Federal de Santa Catarina. Florianópolis.

CASTELLS, Manuel. Sociedade em rede. 6 ed. São Paulo: Paz e Terra, 1999.

CUNHA, Julieta Costa. Inteligência competitiva desenvolvida por redes sociais. 2006. 106f. Brasília. Dissertação de mestrado. Programa de Pós-Graduação em Administração, Universidade de Brasília. Disponível em: http://bdtd.bce.unb.br/tedesimplificado/tde arquivos/61/TDE-2006-08-29T164125Z219/Publico/Julieta\%20Costa\%20Cunha.pdf Acesso em: 20/05/2008.

FERNANDEZ, M. J. Inteligência Competitiva e mudança organizacional: uma validação de modelo em grupo industrial. Universidade regional de Blumenau. Blumenau, 2004.

FLICK, Uwe. Uma introdução a pesquisa qualitativa. 2. ed. Porto Alegre: Bookman, 2004. 
AS REDES DE CONTATOS PESSOAIS E AS PRÁTICAS DE INTELIGÊNCIA COMPETITIVA: UM ESTUDO SOBRE A ARQUITETURA DE RELACIONAMENTO EM UMA EMPRESA DE LOGÍSTICA

HAMEL, Gary.; PRAHALAD, C. K. Competindo pelo futuro: estratégias inovadoras para obter o controle do seu setor e criar os mercados de amanhã. Rio de Janeiro: Campus, 1995.

IACOBUCCI, D. Networks in marketing. Thousand Oaks: Sage Publications, 1996.

KAHANER, L. Competitive intelligence: from black ops to boardrooms - how business gather, analyze, and use information to succeed in the global marktplace. New York: Simon \& Schuster, 1996.

LUTHRA, Anika; DESOUZA, Kevin. Intelligence sharing in virtual teams: managing organizational effects of technology. Journal of Competitive Intelligence and

Management, v. 1, n 3, p. 1-9, Winter, 2003.

MITCHELL, J.C. Networks, norms and institutions. In: BOISSEVAIN, J.; MITCHELL, J.C. (Eds.) Networks Analysis: Studies in Human Interaction. London: Mouton and Company, 1973.

MORGAN, G. Paradigms, metaphors and puzzle solving in organization theory. Administrative Science Quaterly, v.25, n.4, p. 605-622, 1980.

NELSON, Reed. O uso de análise de redes sociais no estudo das estruturas organizacionais. RAE - Revista de Administração de Empresas. Rio de Janeiro: v. 24, n. 4, p. 150-157, out/dez, 1984.

NOLAN, J. Confidential: Uncover Your Competitors Top Business Secrets Legally and Quickly-and Protect Your Own. Nova York: Harper Business/Harper Collins. 1999.

NOHRIA, N. Is a network perspective a useful way of studying organisations? In: NOHRIA, N.; ECCLES, R.G. (Ed.). Networks and organisations: structure, form and action. Boston: Harvard Business School Press, 1992.

OLKKONEN, Rami; TIKKANEN, Henrikki; ALAJOUTSIJARVI, Kimmo. The role of communication in business relationships and networks. Management Decision. v.38, n. 6 . London: 2000.

PASSOS, A. Inteligência Competitiva para pequenas e médias empresas: como superar a concorrência e desenvolver um plano de marketing para sua empresa São Paulo: Editora LCTE. 2005.

PETTIGREW, A. M. The character and significance of strategy process research. Strategic Management Journal. v. 13, n. especial, p. 5-16, Winter, 1992.

PODOLNY, Joel M.; PAGE, Karen L. Network forms of organization. Annual Review of Sociology, v.24, p.57-76, 1998.

POZZEBOM, M.; FREITAS, H.M.; PETRINI, M. Pela integração da inteligência competitiva nos enterprise information systems. Ciência da Informação, v.26, n.3, 1997. Disponível em: http://www.ibict.br/cionline/260397/index.htm Acesso em 15/05/2008.

PRESCOTT, John E.; MILLER, Stephen H. Inteligência Competitiva na prática: técnicas e práticas bem sucedidas para conquistar mercados. Rio de Janeiro: Campus, 2002.

RODRIGUES, Leonel Cezar; RICCARDI, Riccardo. Inteligência competitiva: nos negócios e nas organizações. Maringá: Unicorpore, 2007.

SELLTIZ, Claire; WRIGHTSMAN, Lawrence Samuel; COOK, Stuart Welldford. Métodos de pesquisa nas relações sociais. 2. ed. Sao Paulo: E.P.U, 1987. 
VALENTIM, M.L.P. et al. O processo de inteligência competitiva em organizações. DataGramaZero, Rio de Janeiro, v.4, n.3, jun. 2003. Disponível em: http://www.dgz.org.br/jun03/F I art.htm Acesso em: 10/07/2008.

YIN, Robert K. Estudo de caso: planejamento e métodos. 2. ed. Porto Alegre: Bookman, 2005. 